\title{
Source-Dependent Frequency Content of Ultrashallow Seismic Reflection Data
}

\author{
by G. S. Baker, D. W. Steeples, C. Schmeissner, and K. T. Spikes
}

\begin{abstract}
Seismic surveying within the upper few meters of the Earth's shallow subsurface requires a high-frequency source. To ascertain the important features of such sources, experiments were conducted at test sites in central and eastern Kansas using various impulsive seismic sources (4.5-kg hammer, 30.06 rifle, and .22-caliber rifle) to examine the effects of minimizing source energy on the frequency content of reflection data. Results indicate that the higher energy near-surface seismicreflection sources (e.g., sledgehammer, large-caliber projectiles) lack some of the high-frequency energy exhibited by smaller sources, precluding the detection of reflection signal from ultrashallow depths $(<3 \mathrm{~m})$ at the sites tested. At the test site in eastern Kansas, the .22-caliber rifle yielded more energy above $250 \mathrm{~Hz}$ than either the sledgehammer or 30.06 rifle. At the test site in central Kansas, where three reflective interfaces shallower than $3 \mathrm{~m}$ exist, the .22-caliber rifle with subsonic ammunition yielded the largest amount of energy at frequencies above $300 \mathrm{~Hz}$ and produced the best data.
\end{abstract}

\section{Introduction}

Within the last three years, the ability to describe the upper three meters of the Earth's subsurface seismically has advanced significantly (e.g., Baker et al., 1999b). One main reason is a better understanding of the requirements for successfully collecting data at these shallow depths. This article describes some seismic-source experiments that led to successful detection of seismic reflections at depths of less than $1 \mathrm{~m}$ (Baker et al., 1999a).

Detailed characterization of the shallow subsurface is important not only in environmental, groundwater, and geotechnical engineering applications, but in neotectonics, mining geology, and the analysis of petroleum reservoir analogs as well. Drilling or trenching to assist in characterization, however, is at times imprudent or prohibitively expensive. In such cases, characterizing the upper few meters of the Earth cost-effectively and noninvasively becomes important.

Seismology in its various forms has been used to gather subsurface information for almost a century. Obtaining seismic images from depths shallower than $10 \mathrm{~m}$, however, has not been successful until recently. There are numerous examples of using seismic reflection techniques to examine the upper $100 \mathrm{~m}$ of the earth's subsurface (e.g., Hunter et al., 1984; Goforth and Hayward, 1992; Miller et al., 1995; Baker et al., 1998). However, shallow (less than $10 \mathrm{~m}$ ) reflection seismology has only become possible recently due to improvements in equipment, survey design, and processing procedures (Steeples and Knapp, 1982). Today, there are very few examples of seismic reflections from less than 3- m depth in the refereed literature (e.g., Birkelo et al., 1987; Steeples et al., 1995; Bachrach and Nur, 1998), and only one example showing reflections from less than 1-m depth (Baker et al., 1999a).

There are two basic reasons for using shallow seismicreflection (SSR) methods to address engineering and environmental problems. One reason is to help mitigate existing problems. The SSR methods can be used to evaluate the extent of existing problems, to predict where pollutants will go in the subsurface, and to guide exploratory drilling programs. The other reason is to help design facilities to prevent engineering foundation and environmental problems. Increasingly, SSR methods are being used prior to construction to help assure subsurface integrity at critical locations such as power plants, chemical plants, and waste storage/disposal facilities.

The impulsive sources used in generating energy for seismic-reflection experiments in the near surface are characterized by (1) pulse duration, (2) pulse frequency content, and (3) total energy (Fig. 1). These characteristics are important whether the data collected are to be used in SSR surveying or for deeper hydrocarbon exploration. Pulsecoded techniques such as Vibroseis or MiniSOSIE, which are longer duration time-coded sources, work well in some exploration and near-surface experiments. However, the spatial constraints imposed by ultrashallow seismic data collection (i.e., targets shallower than 3-m depth) prohibit the use of current pulse-coded sources, so they will not be addressed here. 


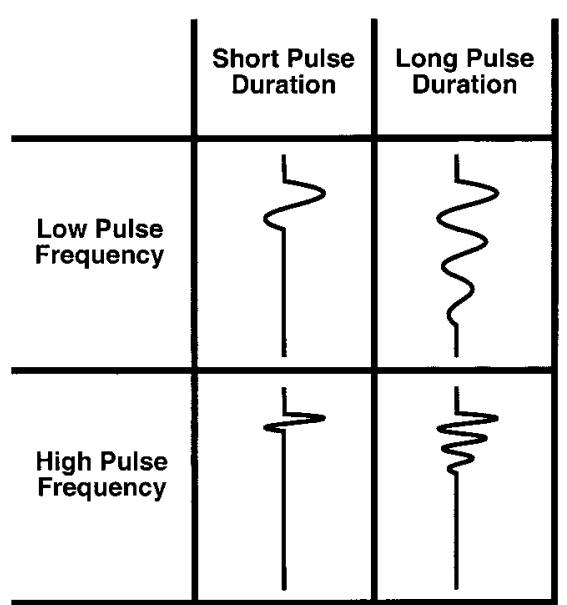

Figure 1. Graphical representation of pulse duration and pulse-frequency content.

Experiments were performed at test sites in Kansas to determine the spectral differences for a $4.5-\mathrm{kg}$ sledgehammer, a 30.06 rifle, and a .22-caliber rifle with long-rifle (supersonic) and short (subsonic) ammunition. The results indicate that when surface conditions are favorable, the .22 rifle generates more high-frequency energy than the sledgehammer or the 30.06 rifle. Additionally, subsonic .22-rifle ammunition was found to generate ultrashallow data that had higher frequencies and better resolution than did supersonic .22-caliber ammunition.

\section{Source Characteristics}

\section{Pulse Duration}

The duration of a source pulse, which can also be expressed in terms of bandwidth, is important because pulses of shorter duration typically allow for better resolution and interpretation than those of longer duration (Fig. 2). Ideally, a deconvolution routine can be used during data processing to compress a long-duration source pulse so that it simulates a shorter pulse. However, several of the basic assumptions underlying deconvolution (Yilmaz, 1987) are often violated with respect to near-surface reflection data (Baker et al., 1998). First, the reflectivity series of the subsurface is assumed to be spatially random, but SSR data often image only one or two reflectors. Second, it is assumed that the source generates a compressional plane wave that impinges on layer boundaries at normal incidence (i.e., a stationary wavelet is preserved from near to far offsets), but SSR data typically consist of wide-angle reflections in which the depth of the reflector is not substantially greater than the length of the geophone spread. Both major assumptions in the convolution model are typically invalid for SSR data; thus, minimizing source-pulse duration is important because deconvolution often will not improve SSR data after they have been collected.

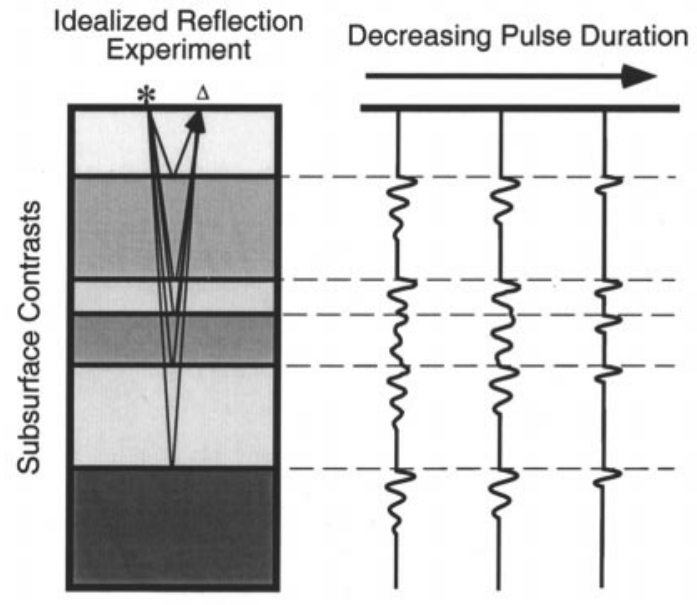

Figure 2. Idealized subsurface interfaces (left) with one-way traveltime traces (right). The traces represent the response of three source pulses at the same frequency but with increasing duration to the interfaces in the subsurface model. The shorter duration pulses better articulate the positions of the closely spaced interfaces.

\section{Pulse Frequency}

The frequency of the source pulse is equally important, primarily because of the relationship between frequency $(f)$ and wavelength $(\lambda)$. Wides (1973) has shown that the vertical resolution potential for a given source is approximately $\lambda / 4$, with

$$
\lambda=V / f
$$

where $V$ is the propagation velocity of the medium through which the source energy is passing and $f$ is the frequency content of the source pulse. Therefore, for site-specific seismic-propagation velocities the vertical resolution potential of the data is directly dependent on the source-frequency content. This assumes a direct relationship between the source pulse and the recorded data when path lengths are only a few meters.

\section{Total Energy}

The various properties of subsurface materials and the physics of propagating waves dictate that source energy will be attenuated as it travels through the subsurface. Because of attenuation, for a given source, the amount of energy traveling from the source through the subsurface to the target and then back to the receivers (with sufficient detectable remaining energy) is limited. Total energy must always be great enough to permit detection of the target. However, as total energy increases, so does cost, environmental impact, and near-source nonlinear deformation. 


\section{Ultrashallow Source Comparison}

Hammer and Rifles

Figure 3 represents a field comparison of raw data collected at a test site in eastern Kansas. The three sources were a $4.5-\mathrm{kg}$ sledgehammer struck on an aluminum plate, a 30.06-caliber rifle fired into a 60-cm-deep prepunched hole, and a .22-caliber rifle with long-rifle ammunition fired into a 30-cm-deep prepunched hole. The sledgehammer and the downhole 30.06 rifle are considered to be fairly standard SSR sources. Analysis of frequency spectra (Fig. 4) reveals that the sledgehammer and 30.06 sources generated more total energy than the .22 rifle. However, the .22 rifle generated more energy at the higher frequencies $(>250 \mathrm{~Hz})$ necessary for ultrashallow seismic-reflection work.

When the .22 rifle is chosen as an SSR source, perform-

\section{Blow w/4.5 kg Sledgehammer}

\subsection{Rifle} .22 Rifle
w/Long Rifle
Ammunition

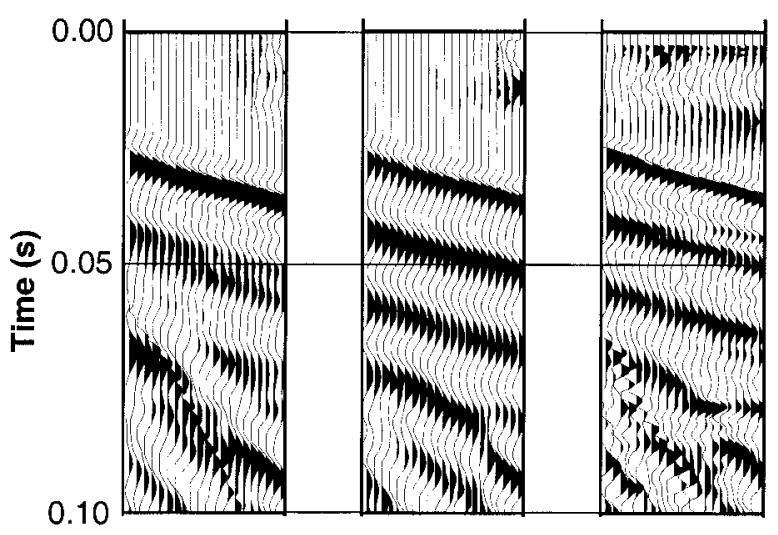

Figure 3. Three raw field files with three different sources recorded in eastern Kansas at the same location with the same receiver line.

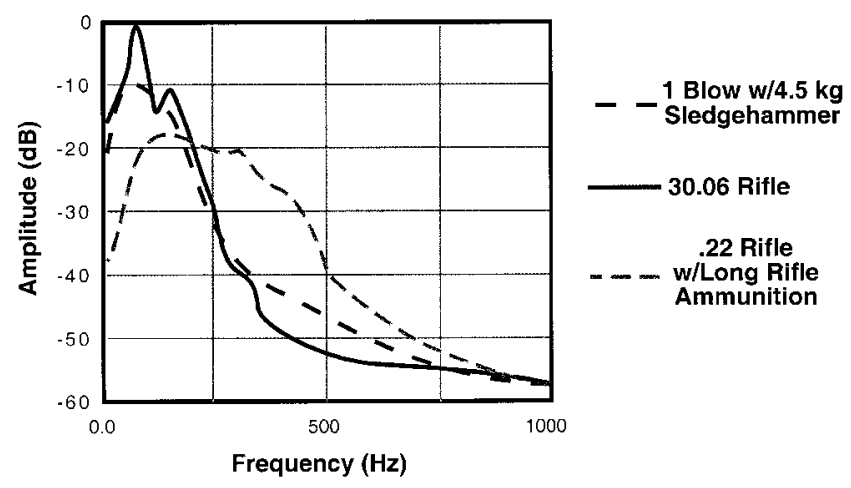

Figure 4. Twenty-four trace averaged amplitude spectra from the field files in Figure 3. Note that the sledgehammer and the 30.06 rifle generated significant energy, but not in the high-frequency range observed when the .22 rifle was used. Data are normalized using true amplitudes for direct comparison. ing appropriate field tests is important to establish whether the reduced source energy will be sufficient to allow the observation of the target(s). In Figure 5, if the target of interest is a reflection at $\sim 80 \mathrm{msec}$, then the sledgehammer or the 30.06-rifle source would work well. If, however, the target of interest is the reflection at $\sim 40$ msec the sledgehammer and the 30.06 rifle do not have the high frequencies or the short-duration source pulse necessary to observe the reflections. Conversely, the .22 rifle generated sufficient energy and frequencies high enough to image the reflection at $\sim 40 \mathrm{msec}$. Comparisons have been obtained from various other areas of unconsolidated material in Kansas, with similar results (Baker, 1999).

\section{Short Versus Long-Rifle Ammunition}

The main differences between the short and long-rifle ammunition are the mass of the bullet and its velocity as it exits the rifle barrel. The short ammunition is $\sim 7 \%$ lighter than the long-rifle ammunition, and the velocity of the short ammunition is $\sim 43 \%$ that of the long-rifle ammunition. Additionally, the short ammunition is subsonic, whereas the long-rifle ammunition is supersonic when fired into the air (Table 1).

Data were collected at a site in central Kansas. When good ultrashallow reflection information was available, results demonstrated that .22-caliber subsonic ammunition

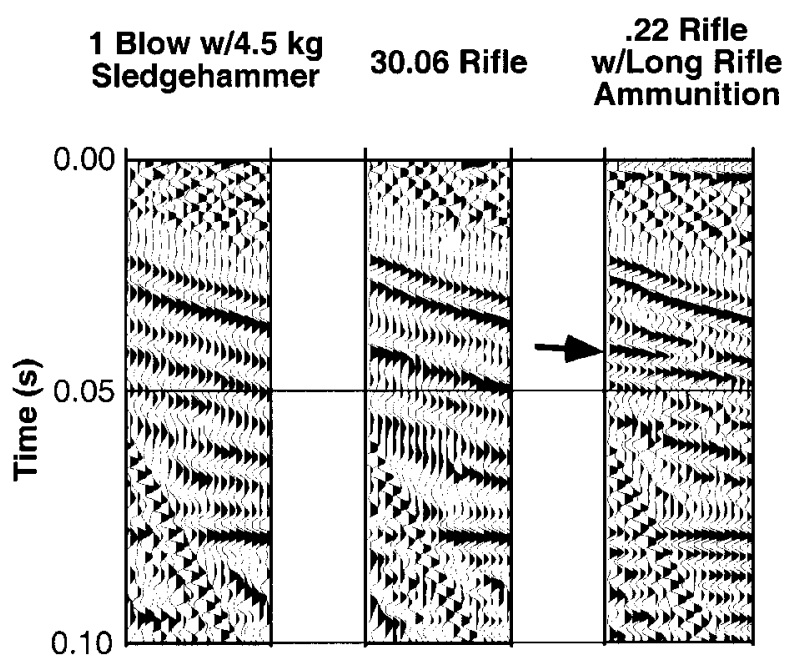

Figure 5. The three field files in Figure 3 with band-pass filtering from 250 to $400 \mathrm{~Hz}$ with $12 \mathrm{~dB} /$ octave slopes. Notice that the reflection at $\sim 40 \mathrm{msec}$ (arrow) was only visible when the .22 rifle was used.

Table 1

Ammunition Specifications

\begin{tabular}{lcc}
\hline Ammunition Type (from Bount, Inc.) & Weight (g) & Muzzle Velocity (m/sec) \\
\hline CCl .22 CB short (\#0026) & 29 & 221 \\
CCl .22 long-rifle Stinger (\#0050) & 32 & 514 \\
\hline
\end{tabular}


generated more energy at higher frequencies than did supersonic ammunition. Figure 6 shows the normalized amplitude spectra for raw data collected using both types of ammunition and demonstrates the frequency differences between the two ammunition types. Figure 7 shows identically processed field files with ammunition type being the only difference. Figure 8 shows the same data sorted as common-midpoint (CMP) gathers to demonstrate that the observed effects were not localized at only a few shot points. Note that in Figures 7 and 8 the signal-to-noise ratio and frequency content of reflections arriving before $\sim 20 \mathrm{msec}$ are higher for the data collected using .22-short ammunition.

Additional results of the .22-rifle ammunition tests are shown in the identically processed, stacked seismic sections in Figure 9. When subsonic ammunition was used, the frequencies of the reflections were higher and more detail was visible between the reflection at $\sim 10 \mathrm{msec}$ and that at $\sim 20$ msec. Although the reflection at $\sim 10 \mathrm{msec}$ appears more coherent when the .22-long-rifle ammunition was used, more detail was observed using the .22 -short ammunition.

\section{Determining $\mathrm{T}_{0}$ for the .22-Caliber Rifle}

The accuracy of the zero-offset time $\left(T_{0}\right)$ is critical for calculating velocity and depth information in all reflection techniques. For ultrashallow seismic-reflection data, a proper determination of $T_{0}$ is even more important because errors of even a fraction of millisecond can cause significant errors in depth determinations. The typical method for calculating $T_{0}$ for the .22 rifle is to attach a piezoelectric switch near the bolt of the rifle and allow the recoil from the explosive acceleration of the bullet to trigger the switch. However, when collecting ultrashallow data using very small geophone intervals with a near-offset geophone about $10 \mathrm{~cm}$ from the shotpoint, field files showed a consistent time delay between $T_{0}$ and the direct arrival phase at $10 \mathrm{~cm}$ offset. This delay was determined to be the lag between the firing of the rifle and the time taken for the bullet to travel down the barrel before striking the ground.

A simple experiment was conducted to determine quantitatively the delay time and back-calculate $T_{0}$ for the .22 rifle. A circuit was created by connecting a thin wire taped over the end of the rifle barrel and collected to a 9-volt battery and a geophone takeout. The rifle was then fired, the seismograph was triggered to start recording using the piezoelectric switch, and the bullet broke the wire and interrupted the circuit (e.g., Figure 10). The response to the broken circuit was an approximation of the impulse response of the seismograph amplifiers. The delay between the zero-offset time recorded by the piezoelectric trigger and the true $T_{0}$ was determined to be $2.5 \mathrm{msec}$ for .22-short ammunition and $1.5 \mathrm{msec}$ for long-rifle ammunition and was used to obtain the correct $T_{0}$ for all data in this article.

\section{Discussion}

Pulse duration, pulse frequency, and total energy are inherent in the type of shallow-seismic source used, but

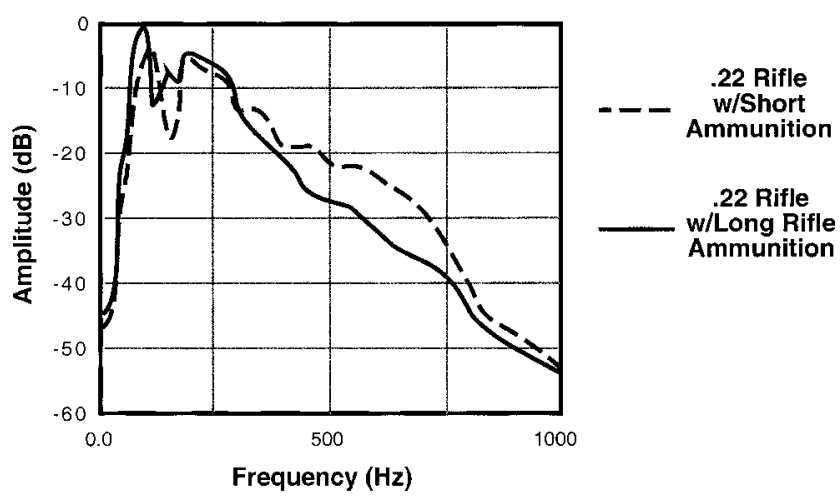

Figure 6. Frequency spectra generated using 24 averaged traces from 6 raw field files collected in central Kansas using two different sources. The .22-short ammunition generates more energy at higher frequencies (between 300 and $750 \mathrm{~Hz}$ ) than the .22-long-rifle ammunition. The spectra are normalized to true amplitudes for direct comparison.
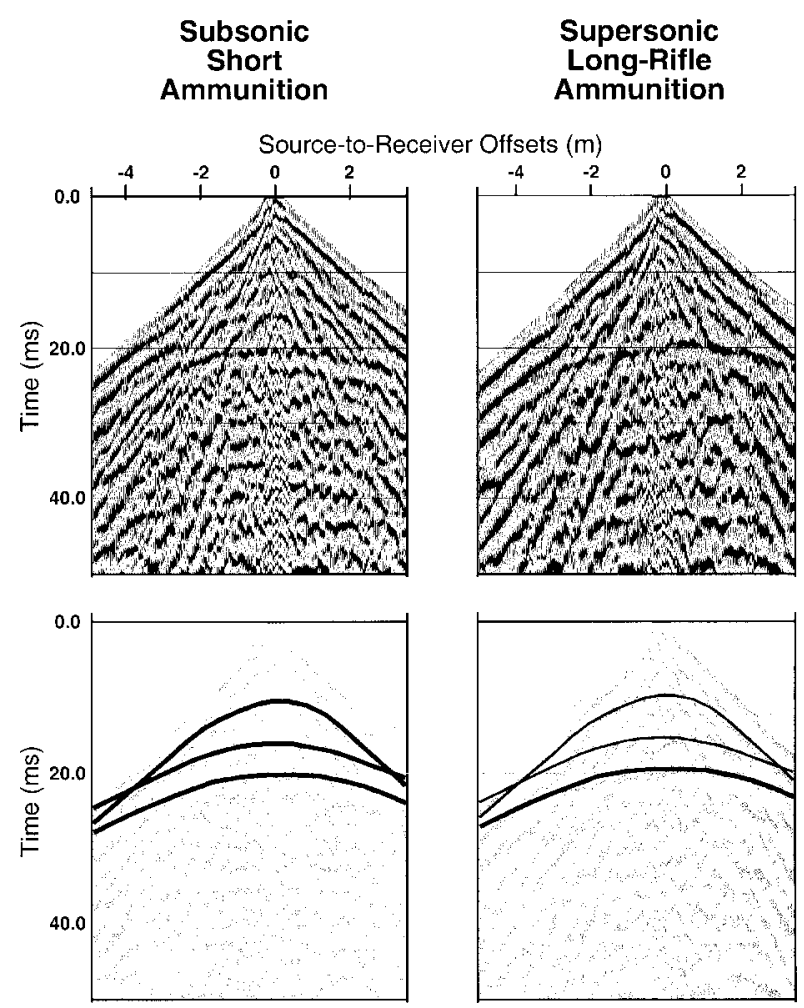

Figure 7. Identically processed field files from data collected in central Kansas (5-msec AGC window; 390 to $600 \mathrm{~Hz}$ band-pass filter with $12 \mathrm{~dB} / \mathrm{oc}-$ tave slopes). The reflection at $\sim 20 \mathrm{msec}$ is from the water table at $\sim 2.2-\mathrm{m}$ depth. The use of .22-short ammunition generated more coherent reflections with higher frequencies at times earlier than $20 \mathrm{msec}$. The ultrashallow reflections in the data collected using long-rifle ammunition are more difficult to interpret. Noise arriving prior to the direct wave has been muted. 


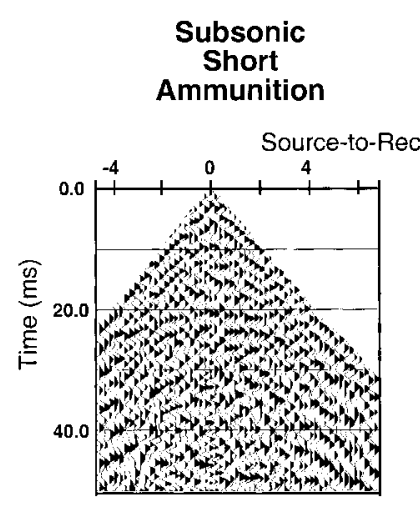

Supersonic Long-Rifle Ammunition
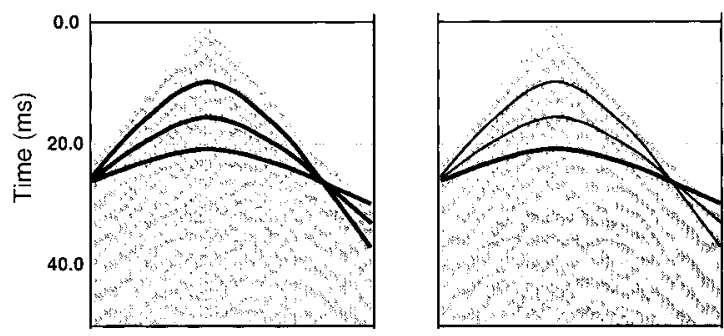

Figure 8. Identically processed CMP gathers from data collected in central Kansas (5-msec AGC window; 390 to $600 \mathrm{~Hz}$ band-pass filter with $12 \mathrm{~dB} / \mathrm{oc}$ tave slopes). The reflection at $\sim 20 \mathrm{msec}$ is from the water table at $\sim 2.2-\mathrm{m}$ depth. The use of .22-short ammunition generated more coherent reflections with higher frequencies at times earlier than $20 \mathrm{msec}$. The reflection at $\sim 10 \mathrm{msec}$ is clear on the short-ammunition data and visible but not coherent on the longrifle-ammunition data; however, the frequency of the reflections is higher using the .22-short ammunition. Noise arriving prior to the direct wave has been muted.

those characteristics also are affected by the elastic properties of the subsurface. Thus, an ideal source does not exist, and the "best" source at one site may not be the best source at the same site under different moisture or soil-compaction conditions or at another site. Several papers discuss source comparisons for SSR data collected at various sites (e.g., Miller et al., 1986, 1992, 1994) and a single site under different soil-moisture conditions and on different days (Baker et al., 1997; Jefferson et al., 1998).

At the test site in eastern Kansas, the standard SSR sources (e.g., sledgehammer, 30.06 rifle) had reduced energy generated above $250 \mathrm{~Hz}$. This could be related to increased nonlinear deformation near the source, decreased coupling into the ground, or increased pulse duration caused by deeper penetration (in the case of higher-energy bullets) or by slower impact velocity (in the case of the sledgehammer). Regardless of the cause, reducing source energy by using a .22-caliber rifle with subsonic short ammunition produced source-pulse characteristics that were more conducive to the collection of ultrashallow reflection data.

At the test site in central Kansas, the .22 rifle with subsonic short ammunition yielded more energy at frequencies
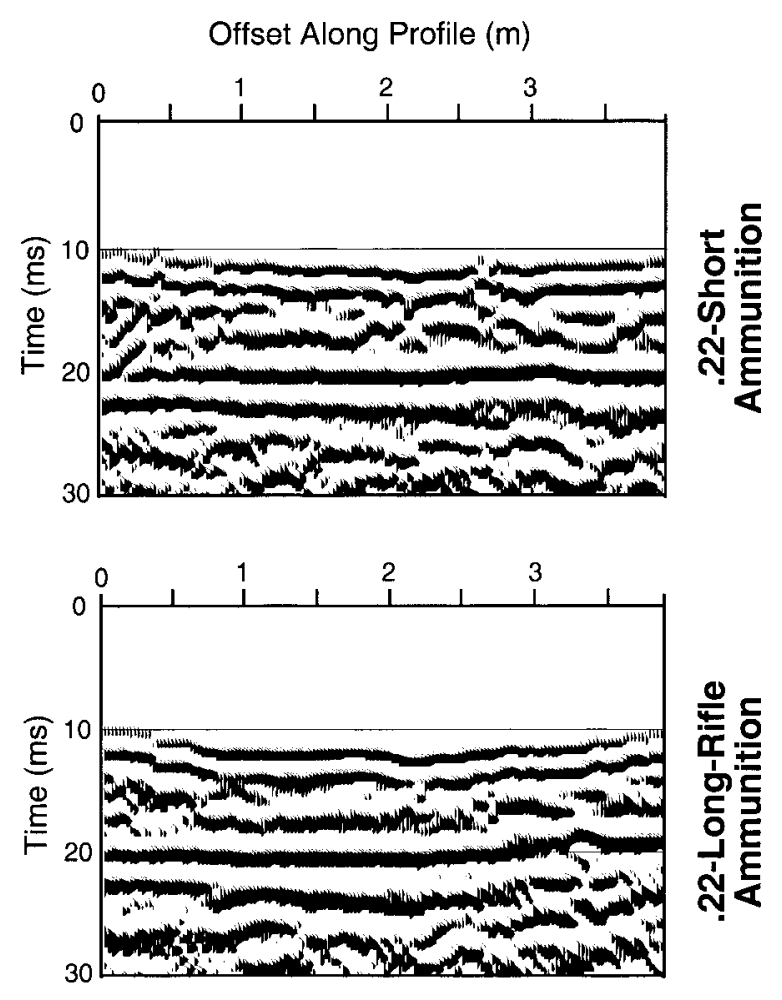

Figure 9. Identically processed, stacked seismicreflection sections of data collected in central Kansas. The reflection at $\sim 20 \mathrm{msec}$ (doublet) from the water table at $\sim 2.2-\mathrm{m}$ depth is better defined and the frequency is higher in the data collected using the .22short ammunition. The reflection at $\sim 10 \mathrm{msec}$ (doublet) is more coherent in the long-rifle-ammunition data but is higher in frequency and shows more detail in the short-ammunition data (i.e., between 10 and 20 msec).

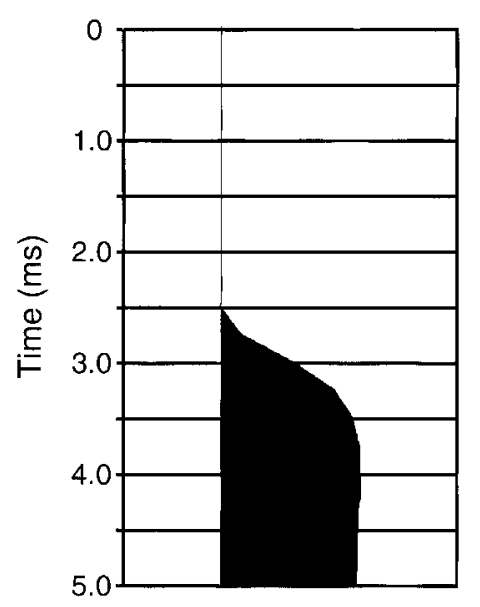

Figure 10. A shaded wiggle-trace field file showing the time delay between the triggering of the piezoelectric switch (time $=0 \mathrm{msec}$ on the vertical axis) and the interruption of a circuit that includes the geophone takeout when the .22-caliber subsonic bullet exited the barrel of the .22 rifle (time $=2.5 \mathrm{msec}$ ). 
above $300 \mathrm{~Hz}$ than the .22 rifle with long-rifle ammunition. Overall, minimizing impulsive source energy at both test sites increased the energy content at frequencies above $\sim 250$ $\mathrm{Hz}$, which is important for ultrashallow seismic-reflection data collection. Therefore, the "best" impulsive ultrashallow seismic source for the test sites in Kansas (.22 rifle with subsonic ammunition) was one with short duration, high frequency, and the minimum energy required for detection the target.

\section{Acknowledgments}

This work was supported in part by the U.S. Department of Energy under Contract DE-FG07-97-ER14826 and by the National Science Foundation under Grant EAR97061218.

\section{References}

Bachrach, R., and A. Nur (1998). High-resolution shallow seismic experiments in sand, Part I: Water table, fluid flow, and saturation, Geophysics 63, 1225-1233.

Baker, G. S. (1999). Seismic imaging shallower than three meters, Dissertation, The University of Kansas, 320 p.

Baker, G. S., D. W. Steeples, and M. Feroci (1997). The time dependence of shallow reflection data, The Leading Edge 16, no. 11, 1663-1666.

Baker, G. S., D. W. Steeples, and M. Drake (1998). Muting the noise cone in near-surface reflection data: an example from southeastern Kansas, Geophysics 63, 1332-1338.

Baker, G. S., C. Schmeissner, D. W. Steeples, and R. G. Plumb (1999a). Seismic reflections from depths of less than two meters, Geophys. Res. Lett. 26, 279-282.

Baker, G. S., D. W. Steeples, and C. Schmeissner (1999b). In situ, highresolution $P$-wave velocity measurements within $1 \mathrm{~m}$ of the Earth's surface, Geophysics 64, 323-325.

Birkelo, B. A., D. W. Steeples, R. D. Miller, and M. A. Sophocleous (1987). Seismic-reflection study of a shallow aquifer during a pumping test, Ground Water 25, 703-709.
Goforth, T., and C. Hayward (1992). Seismic reflection investigations of a bedrock surface buried under alluvium, Geophysics 57, 1217-1227.

Hunter, J. A., S. E. Pullan, R. A. Burns, R. M. Gagne, and R. S. Good (1984). Shallow seismic-reflection mapping of the overburden-bedrock interface with the engineering seismograph—some simple techniques, Geophysics 49, 1381-1385.

Jefferson, R. D., D. W. Steeples, R. A. Black, and T. Carr (1998). Effects of soil-moisture content on shallow-seismic data, Geophysics 63, 1357-1362.

Miller, R. D., S. E. Pullan, J. S. Walder, and F. P. Haeni (1986). Field comparison of shallow seismic sources; Geophysics 51, 1067-1092.

Miller, R. D., S. E. Pullan, D. W. Steeples, and J. A. Hunter (1992). Field comparison of shallow seismic sources near Chino, California, Geophysics 57, 693-709.

Miller, R. D., S. E. Pullan, D. W. Steeples, and J. A. Hunter (1994). Field comparison of shallow seismic sources near Houston, Texas, Geophysics 59, 1713-1728.

Miller, R. D., N. L. Anderson, H. R. Feldman, and E. K. Franseen (1995). Vertical resolution of a seismic survey in stratigraphic sequences less than $100 \mathrm{~m}$ deep in southeastern Kansas, Geophysics 60, 423-430.

Steeples, D. W., and R. W. Knapp (1982). Reflections from 25 feet or less; 1982 Ann. Internat. Mtg., Soc. Expl. Geophys., Expanded Abstracts, 469-471.

Steeples, D. W., B. Macy, C. Schmeissner, and R. D. Miller (1995). Contrasting near-surface and classical seismology, The Leading Edge 14, no. 4, 271-272.

Widess, M. B. (1973). How thin is a thin bed?, Geophysics 38, 1176-1180. Yilmaz, O. (1987). Seismic Data Processing, Society of Exploration Geophysicists, Tulsa, Oklahoma, 526 pp.

Department of Geology

State University of New York at Buffalo

Buffalo, New York

gbaker@geology.buffalo.edu

(G. S. B.)

Department of Geology

University of Kansas

Lawrence, Kansas

(D. W. S., C. S., K. T. S.)

Manuscript received 15 June 1999. 